\title{
DO EXXTASE AO CRIME? UM CONTO POLICIAL BRASILEIRO RECHEADO DE LATIM
}

\author{
Valéria Marta Ribeiro Soares ${ }^{1}$
}

Resumo: Os contos policiais, de Luiz Lopes Coelho, advogado paulista, são pouco conhecidos. Este trabalho visa analisar o conto Do êxtase ao crime?, tanto do ponto de vista estético quanto lingüístico. No ângulo literário, serão analisados os elementos que fazem dele uma ficção policial e, no aspecto lingüístico, serão destacados os termos latinos que causam uma singularidade na obra e ajudam a interpretá-la. Contistas do gênero policial no Brasil são muito raros, devido ao rótulo dado por muitos eruditos de tal gênero ser "uma das mais limitadas entre as formas populares de ficção". Do êxtase ao crime? pode dar ao leitor uma nova visão desse gênero, pois o autor consegue aliar o engenho e a arte na escolha dos vocábulos, especialmente, os latinos, e na criação do mistério, suspense e situações imprevistas do conto em questão.

Palavras-chave: Análise; Conto; Latim.

Abstract: The short detective stories by Luiz Lopes Coelho, a Brazilian lawyer, are not well known. This work aims to analyse the short story 'Do êxtase ao crime?' both from the aesthetic and the linguistic standpoint. From the literary perspective, the elements that make the story part of detective fiction will be analysed and from the linguistic point of view, the Latin terms that make the story unique and that help in its comprehension will be highlighted. Short-story writers in Brazil are very rare, because many scholars consider this kind of literature "one of the most limited among the popular forms of fiction". 'Do êxtase ao crime?' can give the reader a new vision of this genre, because the author combines ingeniousness and art in the words chosen, especially the Latin words, and in the creation of mistery, suspense and unpredictable situations.

Key words: Analysis; Short story; Latin.

\section{CONSIDERAÇÕES INICIAIS}

Refletir sobre a hipótese de um homem apaixonado ser capaz de matar a amante, após uma relação íntima, é a razão do conto ser denominado Do êxtase ao crime?. Os personagens mais importantes são: Doraci (a assassinada), Rogério Vivianich (o amante da vítima e o principal suspeito), Alberto Breugel (o ex-marido de Doraci), Dr. Gerson (o juiz de Direito e também amante da vítima) e Dr. Leite (o delegado e o investigador do caso).

1 Professora de Língua Latina no Departamento de Letras e Artes da Universidade Estadual de Feira de Santana - UEFS; Mestre pelo Programa de Pós-graduação em Literatura e Diversidade Cultural da UEFS. Endereço eletrônico: lelasoares@oi.com.br. 
O texto é dividido em onze partes com um subtítulo específico para cada uma delas: "Dia do confronto"; "Dia de Doraci"; "Dia da morte"; "Dia de Alberto"; "Dia de Rogério"; "Dia de mim mesmo"; "Dia da imprensa"; "Dia do desespero"; "Dia da conversa"; "Dia do delegado"; "Dia do fim e Dies irae".

O conto policial brasileiro Do êxtase ao crime?, de Luiz Lopes Coelho (19111975), será objeto de análise estética e lingüística. O objetivo do estudo é observar a forma e o conteúdo da obra em questão. Sabe-se que a literatura policial no Brasil não alcançou a popularidade que outros gêneros literários conseguiram, porque muitos estudiosos a vêem como um subgênero, uma subliteratura. Esse trabalho será uma boa oportunidade de rever essa idéia preconceituosa.

Pode-se, também, notar a importância que a língua latina adquire na elucidação de várias passagens do texto, já que quem conta a história é o juiz de Direito e, por isso, o estudo das dezoito expressões, que aparecem no conto, terá seu espaço reservado.

\section{RELATO E ANÁlise do CONTO}

As estórias de Luiz. Lopes Coelho são muito boas, mas o que nos parece mais importante em sua obra é a criação de um detetive nacional na fiçãa policial brasileira. O Doutor Leite é uma boa figura que faz com que esquecamos, sem sacrifício, vários detetives estrangeiros [...] (Paulo de Medeiros e Albuquerque, 1979, p. 213).

Do êxtase ao crime? é um conto policial extraído do livro $O$ homem que matava quadros, de Luiz Lopes Coelho - advogado paulista e criador da detective story no Brasil - que trata da morte da personagem Doraci e dos seus possíveis assassinos, todos investigados pelo delegado Leite. A vítima foi morta um pouco depois do ato sexual, daí o título do conto.

O principal suspeito era o médico Rogério Vivianich, brasileiro, solteiro e amante da vítima, porque, tinha feito sexo com a vítima momentos antes. Os outros dois suspeitos eram Alberto Breugel, seu ex-marido, e Dr. Gerson, juiz de Direito, advogado de divórcio da morta e seu amante mais antigo.

Alberto Breugel livra-se da suspeita, porque um oficial de justiça o acompanhara até o apartamento de Doraci no dia do crime e testemunhou a seu favor. Todos os indícios do delito levavam a Rogério Vivianich, porém este demonstrava muito amor por ela em seus depoimentos, causando dúvidas ao responsável pelas investigações, o delegado Leite, sobre a autoria do homicídio.

Dr. Gerson somente foi investigado pelo delegado, porque descobriu-se um cheque em seu nome para a locação do apartamento de Doraci. Este último suspeito foi o homicida, já que viu sua amante fazendo sexo com Rogério Vivianich. Não suportando o ciúme, a matou por estrangulamento. 
O problema de desvendar o crime passional era que a porta do apartamento da defunta não fora arrombada e as suspeitas só caíam sobre Rogério. Passaram-se apenas cinqüenta segundos entre o horário que Rogério teria deixado o prédio e o assassinato da moça, pouco tempo para alguém abrir a porta do apartamento, matar a moça, trancar a porta e fugir.

O delegado chegou à conclusão de que o Dr. Gerson era o assassino, quando deduziu que o juiz também estava dentro do apartamento no dia do delito, além de Doraci e Rogério.

Nesse sucinto relato, percebe-se quase todos os ingredientes básicos para a literatura de gênero policial discriminados por Kurt Steel, redator de "detective story" do Dictionary of World Literary Terms sob a direção de Joseph T. Shipley (s.d., p. 1011):

1. O crime aparentemente perfeito e insolúvel;

2. O suspeito, injustamente acusado por enganadoras evidências circunstanciais;

3. A incapacidade da polícia para esclarecer o mistério;

4. O olhar percuciente e a inteligência sagaz do detetive, cujos hábitos excêntricos fazem prever tais virtualidades;

5. O auxiliar do detetive, ser admirativo mas de mente pouco ágil, que conta a história;

6. O axioma de que as evidências superficialmente convincentes são sempre falazes.

Dentre os elementos apresentados por Kurt Steel, no livro Maravilhas do conto policial, o único que faltou, na história de Luiz Lopes Coellho, foi o auxiliar do detetive, de mente pouco ágil, que narra a história, como normalmente ocorre nas ficções policiais do inglês Sir Arthur Conan Doyle, em que aparece sempre o fiel escudeiro Watson para auxiliar o detetive Sherlock Holmes. Entretanto, esse fato não diminuiu o valor estético da obra, pois o contista brasileiro abordado, de acordo com Osman Barbosa (s.d., p. 9) - responsável pela introdução do livro O homem que matava quadros - é

autêntico mestre do gênero, considerado pela crítica o Simenon brasileiro, o autor sabe inventar enredos intrincados, deslindá-los logicamente, criar atmosfera adequada e, ao mesmo tempo, dar a cada uma de suas páginas tratamento literário da melhor qualidade.

Osman Barbosa aproxima o estilo de Luiz Lopes Coelho ao de Georges Joseph Christian Simenon (1903-1989), escritor belga, radicado na França. O personagem Maigret, de Georges Simenon, assemelha-se do personagem Doutor Leite, de Luiz Lopes Coelho, por esses seres ficcionais terem sido criados como policiais profundamente humanos. Observe-se o que Paulo de Medeiros e Albuquerque 
(1979, p. 140-141), em seu livro O mundo emocionante do romance policial, comenta a respeito de Maigret:

Semelhante a Maurice Leblanc que se confessou vencido pela personagem que criou, Maigret começou também a tomar conta de Simenon. Sucedem-se os romances em torno do detetive diferente, chefe de família e sobretudo tão classe média francesa, com mais precisão parisiense e profundamente humano. Maigret cresce, toma conta não só do leitor francês, mas atravessa fronteiras, é traduzido e em toda parte alcança êxito. É levado ao cinema, à televisão e até mesmo às estórias em quadrinhos.

Sandra Lúcia Reimão (1983, p. 11), em O que é romance policial, revela que a narrativa policial de detetive é chamada, também, de romance de enigma e, para a autora, é a denominação mais adequada, devido a esse gênero partir de um contexto de enigma. "O enigma atua, então, como desencadeante da narrativa, e a busca de sua solução, a elucidação, o explicar o enigma, o transformar o enigma em um não-enigma é o motor que impulsiona e mantém a narrativa; quando se esclarece o enigma, se encerra a narrativa", segundo ela mesma. Em Do êxtase ao crime?, enquanto dura o mistério acerca da morte de Doraci, o enredo prende a atenção do leitor. Descoberto o homicida, a história se acaba. Lembre-se que o precursor do gênero foi Edgar Allan Poe (1809-1849) e ele enfatizou a necessidade, em seus contos, de prender a atenção do leitor, de manter, justamente, o enigma.

O delegado Leite faz o papel de detetive e quem conta a história é o próprio assassino, isto é, o personagem-narrador, Dr. Gerson, o juiz de Direito. Portanto, a narração é em primeira pessoa e os fatos são conduzidos para um desfecho inesperado: qual leitor suporia que o autor do crime é o próprio contador da história policial e que narrará sua própria morte?

Um dado a ser levado em conta para análise do conto Do êxtase ao crime? é a profusão de expressões latinas e é isso que mais será destacado de agora em diante. $\mathrm{Na}$ literatura policial de Conan Doyle (1859-1930), Sherloch Holmes faz uso do latim também. O conto, por exemplo, $O$ pé-do-diabo, do livro $O$ último adeus de Sherloch Holmes usa o nome latino da planta venenosa, "Radix pedis diaboli", responsável pela morte de personagens desse conto.

Note-se que quem narra, no conto, é um juiz e, por isso ele utiliza várias expressões latinas calcadas do Direito Romano, que é a base do Direito contemporâneo. As expressões latinas aparecem do início ao fim da história e é necessário o desvendamento das tais, que perfazem um total de dezoito, para o entendimento de algumas passagens do texto.

O texto é dividido em onze partes com um subtítulo específico para cada uma delas e, em quase todas, há palavras ou sentenças em latim. Certas expressões latinas são utilizadas com o objetivo de revelar a erudição do juiz, pois o Dr. Ger- 
son mostra-se orgulhoso, vaidoso da sua profissão. Outras contribuem para impactar o texto.

Na primeira parte - "Dia do confronto" - o juiz de Direito discorre sobre a idéia de que somente deputados, senadores e ministros de Estado possam cometer faltas éticas no exercício de sua profissão, utilizando, para isso, a fórmula de cortesia “data venia", 'com a devida vênia' (RÓNAI, 1980, p. 49):

[...] ao juiz de Direito veda-se o gosto pronunciado por mulheres, jogo ou práticas levianas, ao passo que os deputados, senadores e ministros de Estado continuam incólumes se, porventura, cedem a qualquer daquelas tentações. Data venia, é uma injustiça com os membros do Poder Judiciário... (COELHO, s. d., p. 11).

Para expressar, ainda nessa mesma parte, seu envolvimento repentino com o caso de Doraci, aparece a expressão "ex abrupto", 'de improviso', 'intempestivamente’ (RÓNAI, 1980, p. 62): “[...] Tomei todas as cautelas, poupei atitudes, abafei meus passos, mas a barragem não deteve a catadupa dos fatos e, ex abrupto, sentime carregado por eles" (COELHO, s.d., p. 11).

Na segunda parte - "Dia de Doraci" - o texto faz uso de duas expressões latinas: “in limine”, 'no limiar', 'de saída', 'desde logo' (RÓNAI, 1980, p. 90) e “de visu”, 'por ter visto’ (RÓNAI, 1980, p. 52). "In limine” abre o parágrafo e revela como o relacionamento entre Doraci e o Dr. Gerson começou a partir de um olhar súplice dela:

In limine, levei a súplica do olhar a conta da pretensão logo transmitida de ver fixada em tantos cruzeiros a pensão alimentícia devida pelo marido, do desquite. Mas, quando se retirou, perdurava ainda o olhar de inquietação mansa, mesclada à doçura de um apelo (COELHO, s.d., p. 12).

Dr. Gerson tenta demover Doraci de continuar recebendo a pensão alimentícia de seu ex-marido e, como não podia investigar na vara criminal, sem levantar suspeitas sobre seu caso amoroso, resolve confiar nas palavras dela que dizia ter desistido da pensão. A expressão "de visu” é utilizada para quem quer ver para crer:

[...] Transferido para uma vara criminal, era-me difícil, sem despertar reparos, verificar - de visu - se realmente desistira da pensão. Ademais, acreditei nela, como aliás sempre aconteceu quando ilustrava suas frases com o olhar de prece (COELHO, s.d., p. 12).

Na terceira parte - "Dia da morte" - chega a vez da expressão "ab irato", 'num impulso de cólera' (RÓNAI, 1980, p. 17). Tal expressão surge para explicar a razão da morte de Doraci. Teria o criminoso praticado sexo com a vítima e, num impulso de cólera, a matado em seguida; resumidamente: do êxtase ao crime: "[...] Denunciavam, consoante comentários, a suprema brutalidade do assassino, que teria passado, ab irato, do êxtase ao crime" (COELHO, s.d., p. 12). 
Na quarta parte - "Dia de Alberto" - o juiz de Direito utiliza as expressões "ab imo pectore", 'do fundo do coração' (RÓNAI, 1980, p. 17) e "cum grano salis", 'com uma pedrinha de sal', 'com certa ressalva' (RÓNAI, 1980, p. 46). “ $A b$ imo pectore" aparece para mostrar o sentimento poderoso que o ex-marido, Alberto Breugel, nutria por sua ex-mulher e "cum grano salis" é utilizada para deixar, nas entrelinhas, que Alberto Breugel não acreditava que Doraci continuasse sozinha em seu apartamento e, portanto, ele não se sentia disposto a continuar pagando pensão alimentícia a ela que, além do mais, tinha emprego fixo:

Alberto Breugel foi o primeiro homem a atender às súplicas do olhar de Doraci. Atendeu a elas em plenitude, ab imo pectore, até o altar [...].

[...] Insinuava maldosamente, cum grano salis, que outras rendas marginais auxiliavam a economia caseira, pois a suplicada não vivia tão só como alegava... (COELHO, s.d., p. 13).

Na quinta parte - "Dia de Rogério" - o texto apresenta Rogério Vivianich, "médico, jovem e bonitão", por quem Doraci se apaixonou de verdade e pretendia se casar. O juiz de Direito era casado e não tinha tempo suficiente para suprir as carências afetivas da amante, por isso Rogério preenchera as lacunas deixadas pelo juiz, como ele mesmo conta. O juiz só o descobriu no dia do crime. È uma das partes do texto que não apresenta vocábulo em latim. Colocou-se uma expressão de um idioma neolatino, "in petto", um idiomatismo italiano, supostamente pela crença de que essa língua traduz melhor a paixão dela pelo médico: "Soube da sua existência no dia do crime, mas há algum tempo ele existia profundamente - in petto - no coração de Doraci [...]” (COELHO, s.d., p. 14).

$\mathrm{Na}$ sexta parte - "Dia de mim mesmo" - o juiz, com seus cinqüenta anos, se compara ao novo amante, Rogério Vivianich, e reflete como seus sentimentos demonstrados em atitudes obsoletas e canhestras, em relação às do jovem médico, estavam perdendo espaço no coração de Doraci. Recrimina-se por ter se envolvido com a moça mais do que com o Direito puro. Diz sua idade e se descreve fisicamente com suas numerosas rugas na testa e no canto dos olhos, palidez da pele e cabelos brancos e acentua sua velhice com a expressão "et reliqua", 'e o restante' (RÓNAI, 1980, p. 62), que equivale a "et cetera" e a "et caterva" (RÓNAI, 1980, p. 61), como a dizer que envelhecera também para o amor:

Acuado pelo desastre amoroso, olho-me no espelho: atrás de mim, meio século percorrido noto, pela primeira vez, o branco remontando o alto da cabeça, a opacidade da pele a insinuar-se decididamente, as rugas, em condomínio, na testa e no canto dos olhos. Et reliqua [...] (COELHO, s.d., p. 14).

Na sétima parte - "Dia da imprensa" - Dr. Gerson revela o sensacionalismo da imprensa, ao tentar contar sobre a morte de Doraci. Para isso, um dos repórteres exagerou no mistério envolvendo o corpo dela encontrado no quarto 188 A Cor das Letras - UEFS, n. 8, 2007 
fechado. O juiz utiliza, então, a expressão "ab absurdo", 'partindo do absurdo' (RÓNAI, 1980, p. 17):

Nas primeiras notícias um dos repórteres, por certo o mais leviano, lançava - ab absurdo - a hipótese do quarto fechado, procurando enriquecer o mistério que já emoldurava a morte de Doraci. Mas logo depois esclareceram ser a fechadura de duplo comando [...] (COELHO, s.d., p. 14-15).

Ainda, nessa mesma parte, narra a ida do ex-marido acompanhado de um oficial de justiça ao apartamento de Doraci e seu cruzamento no elevador com Rogério Vivianich. Alberto Breugel quer que o oficial de justiça extraia dela detalhes financeiros que comprovem que ele pode cancelar a pensão alimentícia. Ele quer saber o “quantum”, 'quanto' (FARIA, 1956, p. 802) do ordenado de sua exmulher e se vive com alguém. Porém, ele chega atrasado ao flagrante e ela, depois, é encontrada morta no seu apartamento por dois soldados da Radiopatrulha e pelo zelador, que estranhou ela não ter ido trabalhar. Ainda a expressão latina "in loco", 'no próprio lugar' (RÓNAI, 1980, p. 90) elimina qualquer suspeita do crime por estrangulamento ter sido praticado pelo ex-marido, já que o oficial de justiça o teria acompanhado e ficou "in loco", esperando Doraci na portaria do edifício para intimá-la, questionando o zelador sobre hábitos dela:

Apertou o botão do 6o. andar, onde desceu, sempre em companhia do oficial de justiça, a quem solicitou tocasse a campainha da porta de entrada e intimasse Doraci para prestar esclarecimentos sobre o contrato de locação do apartamento, valor do aluguel, fiador, e sobre a qualificação do seu emprego e o quantum do ordenado. Aguardaria o resultado, escondido atrás da coluna, perto da escada.

Ninguém atendeu aos seguidos toques, perfeitamente audíveis do lado de fora. Desceram. Alberto foi embora e ficou in loco o oficial de justiça, na portaria, aguardando a chegada de Doraci para intimá-la. Passaram-se duas horas. Procurou, então, o zelador para conhecer os hábitos de Doraci [...] (COELHO, s. d., p. 15).

Na oitava parte - "Dia do desespero" - o juiz revela que o principal suspeito do estrangulamento era o médico. Comparou-se seu comportamento desesperado, ao receber a notícia da morte da amada, a de personagens da literatura clássica e universal: Romeu, Cirano, Werther, Dirceu, Salviati. No princípio, a mídia e a polícia desconfiaram da atitude do médico, ridicularizando-o, todavia, depois, o meio policial e a imprensa começaram a se interessar pelo caso, a admirar o médico e a pôr em descrédito o ex-marido, já que apenas o oficial de justiça era seu álibi, única testemunha de que Alberto Breugel não entrara no apartamento e há o axioma de Direito citado no texto, em latim e de forma incompleta, que diz "Testis unus, testis nullus", 'uma só testemunha, nenhuma testemunha' (RÓNAI, 1980, p. 172): 
[...] Os repórteres, dois deles principalmente, deram relevo à inusitada reação e, contaminados pela ardência do espetáculo, passaram a não compreender como Rogério teria estrangulado Doraci. Chegaram até a insinuar dúvida sobre a autoria do delito. Outro focalizava, agora, com mais consistência, o comportamento do marido escudado tão-somente na palavra do oficial de justiça. Testis unus... (COELHO, s.d., p. 16).

Rogério fora ao apartamento contar-lhe a novidade: seria nomeado para o cargo de médico de um serviço do Governo estadual e poderiam se casar. Não podia demorar, pois ia agradecer a nomeação ao Secretário de Saúde em hora marcada. Houve uma rápida relação sexual e, após isso, o encontro de Rogério, no elevador, com Alberto Breugel e o oficial de justiça. O juiz não apareceu como amante de Doraci na imprensa.

Na nona parte - "Dia da conversa" - há o momento crucial do conto com o diálogo travado entre o Dr. Leite, delegado à beira dos cinqüenta anos, de cabeleira embranquecida, pele lisa e fulgor nos olhos e o Dr. Gerson, o juiz de Direito e personagem-narrador dessa história policial. O delegado deduz que o Dr. Gerson era também amante da morta, por ter encontrado um cheque de valor alto, em nome do juiz para locação do apartamento dela, no edifício "Príncipe de Gales", edifício este que possuía apenas um apartamento por andar, sendo o de Doraci localizado no sexto andar e, no sétimo, para álibi do juiz, morava um livreiro que importava livros de Direito em pequena escala, bastante freqüentado por advogados, juízes, professores, ponto de reunião e conversa. Ele descia pela escada para seus encontros amorosos com ela, subia novamente ao sétimo andar e pegava o elevador, sem se fazer notar. Dr. Leite descobriu, além disso, que o Dr. Gerson conseguiu a nomeação de sua amante como funcionária da Secretaria de Justiça. Dr. Leite prometeu discrição nas investigações, para o nome do magistrado não aparecer na imprensa, caso o juiz não fosse o culpado.

Três expressões latinas estão nessa parte: “ex-vı”, 'em virtude de' (RÓNAI, 1980, p. 65); “ipsis verbis" que apresenta o mesmo sentido de ipsis litteris, 'textualmente', 'literalmente', 'palavra por palavra' (RÓNAI, 1980, p. 94); e "Fama volat', 'a fama voa'. Nem por força de ser juiz criminal, Dr. Gerson teve oportunidade, anteriormente, de conhecer e conversar com o Dr. Leite. Detalhou no conto seu diálogo com ele e, em virtude de o juiz ser um homem público e famoso, Dr. Leite foi sigiloso, ao saber de seu envolvimento no caso. Abaixo, estão os três fragmentos do conto, onde as três expressões aparecem:

Conhecia o delegado Leite por suas intervenções em alguns casos de crimes misteriosos, mas nunca, nem ex-vi da minha qualidade de juiz criminal, tivera a oportunidade de conversar com ele [...] (COELHO, s. d., p. 16).

[...] $\mathrm{O}$ assunto interessava-me sobremaneira e daí poder reproduzir ipsis verbis nosso diálogo [...] (COELHO, s. d., p. 16). 
Agradeci os cuidados com que me cercava: Fama volat.... O delegado retirou-se [...] (COELHO, s. d., p. 18).

Na décima parte - "Dia do delegado" - o Dr Leite faz uma segunda e definitiva visita ao Dr. Gerson para mais esclarecimentos e levanta a hipótese, astutamente, que o juiz estava dentro do apartamento, mais precisamente, dentro do banheiro, e presenciara toda a cena de amor, paixão e sexo entre Doraci e Rogério. Como Rogério insistisse, batendo na porta do apartamento, Dr. Gerson pedira que ela fosse atender, não sabendo que se tratava do outro amante da moça. Ao médico revelar o motivo de sua visita inesperada, os amantes se empolgaram "no desvario do desejo" e ela esqueceu, por completo, de que o Dr. Gerson estava no banheiro testemunhando tudo. Ele a matou, assim que o médico se foi, e fugiu. Todo seu feito alcançou a marca de cinqüenta segundos.

Na décima primeira e última parte - "Dia do fim e Dies irae" (COELHO, s. d., p. 19) - no próprio subtítulo existe uma expressão latina ('Dia da ira'), evocação incompleta do dia do Juízo Final: "Dies irae, dies illa", 'O dia da cólera, que dia aquele’ (RÓNAI, 1980, p. 53). No princípio, Dr Gerson tenta mentir ao Dr. Leite, entretanto, no fim, prevalece sua ética profissional e o juiz faz uma confissão escrita, assumindo o assassínio de Doraci e inocentando Rogério. Para arrematar o conto policial, de forma comovente, finaliza dramaticamente com uma expressão latina "minima de malis", 'dos males o menor' (RÓNAI, 1980, p. 109) para sumariar sua decisão derradeira: suicidar-se com um tiro no coração, evitando tragédias maiores, como o abalo em sua reputação e escândalo em sua família. Eis as passagens finais do conto:

O delegado tinha razão. Na prevalência de seu raciocínio, só havia uma saída: eu estava dentro do quarto. E estava mesmo. $\mathrm{E}$ isso confessei por escrito.

Menti-lhe, afirmei que não. Para ganhar tempo, para enganar-me, para pensar no que fazer. Em respeito à justiça - por mim sempre servida com empenho, eficiência e afetividade - não posso pemitir pague um jovem por crime alheio. E porque sou juiz de Direito, a quem não se permite o paladar das fraquezas, erguerei este revólver até a altura do meu coração.

Minima de malis (COELHO, s. d., p. 19).

Assim como outros tantos contos, este é um convite à aventura e à vida subterrânea, do contraventor e possui um significado metafísico: a luta entre o Crime, alegoria do Mal, e a Lei, alegoria do Bem. Observe-se que o delegado Leite é identificado como um soldado do Bem e, em linhas gerais, como o homem comum, obcecado pela justiça e o juiz de Direito, o Dr. Gerson, é visto como o ente do Mal, aquele ser que precisa de punição. O dado novo nesse conto é que, como o Dr. Gerson, sendo juiz, representa também a Lei como o delegado Leite, ele se vê mesclado de atitudes negativas e positivas. $\mathrm{O}$ mesmo homem que foi capaz de 
matar a amante por ciúme e em defesa de sua honra, teve a probidade de assumir sua culpa em defesa de um inocente e se matou pela vergonha que causava à sua profissão e à sua família.

\section{CONSIDERAÇÕES FINAIS}

A análise lingüístico-literária do conto policial Do êxtase ao crime?, de Luiz Lopes Coelho, foi cumprida. Como foi explanado no desenrolar desse estudo, os elementos da "detective story" aparecem nesse conto, bem como diversas expressões latinas, que auxiliaram no entendimento da obra. Com certeza, não é uma tarefa completa, porque outros estudos podem ser realizados, a partir deste. É necessário que outros trabalhos dessa natureza ocorram, para dar popularidade ao latim que está inserido em várias obras literárias e à literatura detetivesca no Brasil.

\section{REFERÊNCIAS}

ALBUQUERQUE, Paulo de Medeiros e. O romance francês. In: $O$ mundo emocionante do romance policial. 2. ed. Rio de Janeiro: Francisco Alves, 1979, p. 136-153.

ALBUQUERQUE, Paulo de Medeiros e. O romance policial brasileiro. In: Id. O mundo emocionante do romance policial. 2. ed. Rio de janeiro: Francisco Alves, 1979, p. 205-220.

COELHO, Luiz Lopes. Do êxtase ao crime? In: Id. O homem que matava quadros. Rio de Janeiro: Tecnoprint, s.d., p. 11-19.

DOYLE, Sir Arthur Conan. O pé-do-diabo. In: Id. O último adeus de Sherlock Holmes. São Paulo: Melhoramentos, 2001, p. 59-80.

FARIA, Ernesto (Org.). Dicionário escolar latino-português. 2. ed. Rio de Janeiro: MEC, 1956.

REIMÃO, Sandra Lúcia. O que é romance policial. São Paulo: Brasiliense, 1983.

RÓNAI, Paulo. Não perca o seu latim. Rio de Janeiro: Nova Fronteira, 1980.

SILVA, Fernando Correia da. (Org.). Maravilhas do conto policial. São Paulo: Cultrix, s.d. 